\title{
Provision of Physics Props and Bilingual E-Book for SMA YPK Merauke
}

\section{Pengadaan Alat Peraga Fisika dan E-Book Bilingual untuk SMA YPK Merauke}

\author{
Desy Kumala Sari ${ }^{\mathrm{a},},{ }^{,}$, Rezky Uspayanti $^{\mathrm{a}}, \&$ Pri Ariadi Cahya Dinata ${ }^{\mathrm{b}}$ \\ ${ }^{a}$ Universitas Musamus, Jl. Kamizaun, Merauke 99611, Indonesia \\ ${ }^{b}$ Universitas Palangka Raya, Jl. Yos Sudarso, Palangka Raya 74874, Indonesia
}

\begin{abstract}
Science is learned by bringing real objects in daily life into the classroom. Therefore, the props are needed in learning science to make it easier for students to observe the concepts of science contained in an object. However, not all schools have good props to use in learning. This dedication to society aims to provide props that can be used as a medium of physics learning at SMA YPK Merauke. The props are accompanied by bilingual guides so that students can learn physics and English at the same time. The devotional activities were carried out through the introduction of props to physics teachers, demonstrations on how to use bilingual tools and guides, and mentoring. At the end of the activity, physics teachers were given a user response sheet to find out the teachers' perception of the props given. The results of the user response sheet show that the props can be appropriately used as a learning medium. Then, more props are needed to be given to schools in Merauke that do not have good props.
\end{abstract}

\begin{abstract}
Abstrak
Sains dipelajari dengan membawa objek yang nyata di kehidupan sehari-hari ke dalam kelas. Oleh karena itu, alat peraga diperlukan dalam belajar sains untuk memudahkan siswa mengamati konsep-konsep sains yang terdapat pada suatu objek. Akan tetapi, tidak semua sekolah memiliki alat peraga yang memadai untuk digunakan dalam pembelajaran. Kegiatan pengabdian masyarakat ini bertujuan untuk menyediakan alat peraga yang dapat digunakan sebagai media pembelajaran fisika di SMA YPK Merauke. Alat peraga tersebut disertai dengan panduan bilingual agar siswa dapat belajar fisika dan Bahasa inggris secara bersamaan. Kegiatan pengabdian dilakukan melalui pengenalan alat peraga kepada guru fisika, demonstrasi cara penggunaan alat dan panduan bilingual, serta pendampingan. Di akhir kegiatan, guru-guru fisika diberikan lembar respon pengguna untuk mengetahui persepsi guru-guru terhadap alat peraga yang diberikan. Hasil lembar respon pengguna menunjukkan bahwa alat peraga dapat digunakan dengan baik sebagai media pembelajaran. Ke depannya, diperlukan lebih banyak alat peraga untuk diberikan kepada sekolah-sekolah di Merauke yang belum memiliki alat peraga yang memadai.
\end{abstract}

(C) 2021 Author(s)

Keywords: Props; Physics; E-Book; Bilingual.

\section{Pendahuluan}

Belajar fisika berarti belajar memvisualisasikan fenomena fisis yang abstrak. Hal ini didasarkan dari definisi ilmu fisika, sehingga dalam proses pembelajaran tidak semata-mata merupakan pemberian informasi saja dari guru kepada

\footnotetext{
* Corresponding author:

E-mail address: sari_fkip@unmus.ac.id (Desy Kumala Sari)
} 
peserta didik. Oleh karena itu, kegiatan memvisualisasikan fenomena fisis yang abstrak tidak hanya dilakukan oleh peserta didik namun harus dibimbing oleh guru (Dinata \& Suparwoto, 2018). Dengan demikian, seorang guru fisika memerlukan alat peraga fisika yang dapat memberikan gambaran secara jelas terkait memvisualisasikan fenomena fisis yang abstrak untuk dijelaskan kepada peserta didiknya. Permasalahan muncul ketika guru tidak mampu menghadirkan alat peraga dalam mempelajari materi yang cukup abstrak dalam fisika. Sehingga guru hanya akan menjelaskan persoalan fisika dengan abstrak. Hal ini menyulitkan peserta didik dalam memahami materi tersebut. Padahal, Widiyatmoko \& Pamelasari (2012) mengungkapkan kompetensi guru dapat dikembangkan melalui pengembangan karya inovatif. Karya yang dimaksud dapat berupa teknologi tepat guna termasuk didalamnnya membuat atau memodifikasi alat peraga/praktikum. Alat peraga dalam pembelajaran digunakan untuk membantu peserta didik dalam meningkatkan keterampilan dan pengetahuan, mengilustrasikan dan memantapkan pesan dan informasi, serta menghilangkan ketegangan dan hambatan rasa malas yang muncul pada peserta didik (Octaviana \& Supriyono, 2017). Keterbatasan alat peraga untuk kegiatan praktikum maupun demonstrasi juga menjadi penyebab guru kurang kreatif dalam merancang kegiatan pembelajaran (Pujani, 2015).

Berdasarkan hasil wawancara dengan guru fisika di SMA YPK Merauke diperoleh informasi bahwa alat peraga fisika di sekolah tersebut masih kurang. Padahal, alat peraga merupakan media belajar yang dapat dimanfaatkan untuk memvisualisasikan materi fisika yang cukup abstrak (D. Sari et al., 2019; D. K. Sari et al., 2018). Penggunaan alat peraga dalam pembelajaran berarti mengoptimalkan fungsi seluruh panca indra peserta didik (Dinata et al., 2020). Melalui alat peraga peserta didik dapat meningkatkan efektivitas belajar dengan melihat, mendengar, meraba, serta mnggunakan pikirannya secara logis dan realistis (Widiyatmoko \& Pamelasari, 2012). Penelitian yang dilaksanakan Wahyuningsih (2005) menunjukkan bahwa alat peraga dapat mengefektifkan kegiatan pembelajaran fisika. Selain itu, alat peraga dapat menumbuhkan motivasi belajar peserta didik sehingga proses pembelajaran (Yunita \& Ilyas, 2019) tidak membosankan dan monoton. Dengan demikian perlu adanya penyediaan alat peraga fisika di SMA YPK Merauke untuk mendukung pelaksanaan pembelajaran.

SMA YPK Merauke merupakan salah satu sekolah tingkat menegah atas yang berada di Merauke. Sekolah ini termasuk sekolah swasta milik Yayasan Pendidikan Kristen di tanah Papua yang telah terkareditasi B. Kurikulum yang diterapkan disekolah ini adalah kurikulum 2013. Berdasarkan hasil observasi dan data dari dapodik dikdasmen, diperoleh informasi bahwa pegawai yang bekerja di SMA YPK Merauke terdiri dari 28 orang guru dan 5 orang tenaga pendidik (Kemdikbud, 2020). Sekolah ini terdiri dari 14 ruangan kelas, 6 ruang laboratorium, dan 1 ruang perpustakaan. Ketersediaan laboratorium sebanyak 6 ruangan sebenarnya tidak menjamin pengelolaannya dengan benar. Berdasarkan informasi dari guru fisika bahwa beberapa laboratorium di SMA YPK Merauke di jadikan ruangan kelas karena pertimbangan kurangnya ruang kelas untuk melaksanakan kegiatan pembelajaran. Laboratorium yang digunakan sebagai ruang kelas tidak lagi memungkinakan untuk dilakukan kegiatan praktikum di laboratorium. Dengan demikian, pengadaan alat peraga sebagai media pembelajaran di dalam kelas maupun di luar kelas menjadi sangat perlu.

Pengadaan alat peraga fisika dapat mempermudah guru dalam memperoleh alat peraga yang cocok digunakan dalam pembelajaran fisika. Alat peraga dalam kegitan ini dibuat dengan menggunakan bahan-bahan yang mudah ditemukan disekitar lingkungan. Hal ini bertujuan untuk memanfaatkan barang-barang yang masih dapat digunakan, serta mengajarkan peserta didik agar cinta terhadap lingkungan disekitar. Alat peraga dapat dikembangkan sesuai dengan tujuan pembelajaran dengan memanfaatkan potensi dan sumberdaya yang tersedia (Dinata et al., 2018; Kause, 201 9). Pengembangan alat peraga dapat memanfaatkan bahan-bahan lokal sehingga dapat menghasilkan alat peraga berbasis budaya lokal (Preliana, 2015). Selain itu, alat peraga juga dapat dikembangkan dengan memanfaatkan sampah rumah tangga maupun sampah industry sehingga dapat membantu meminimalisir pencemaran lingkungan (Fitriani, 2013).

Alat peraga fisika tidak lengkap jika tanpa buku panduannya. Adanya buku panduan dapat mempermudah guru dalam menjelaskan penggunaan alat peraga fisika yang digunakan dalam pembelajaran kepada peserta didik. Agar panduan penggunaan dapat di akses dengan mudah, panduan penggunaan alat peraga fisika dibuat dalam bentuk elekttronik book. Tujuannya agar dapat diakses menggunakan computer, PC, maupun smartphone. Konten alat peraga juga dilengkapi dengan dua bahasa (bilingual) yakni bahasa Indonesia dan bahasa inggris. Tujuannya agar guru maupun peserta didik terbiasa menggunakan bahasa inggris dalam bidang fisika selain itu, juga mengingat bahwa bahasa inggris merupakan bahasa internasional. 


\section{Metode}

Kegiatan pengabdian ini dilaksanakan di sekolah mitra yaitu SMA YPK Merauke selama 3 (tiga) hari. Metode pengabdian yang digunakan adalah dengan pendampingan. Terdapat tiga kegiatan yang dilaksanakan yakni pegadaan dan pengenalan alat peraga fisika dan e-book panduan penggunaan alat peraga fisika bilingual (07 Oktober 2020), pendampingan penggunaan alat peraga fisika (09 November 2020), dan monitoring dalam pembelajaran fisika (12 November 2020).

Kegiatan pengabdian dimulai dengan melaksanakan analisis kebutuhan melalui wawancara dengan guru fisika pada sekolah mitra. Selanjutnya dibuat alat peraga, panduan penggunaan alat peraga, menerjemahkan panduan, dan membuat e-book panduan penggunaan alat peraga. Setelah alat peraga dan panduan penggunaan bilingual dibuat, dilakukan kegiatan penyerahan dan pengenalan alat peraga fisika di sekolah mitra. Kegiatan kemudian dilanjutkan dengan pendampingan dan monitoring penggunaan alat peraga fisika dan e-book panduan penggunaan alat peraga fisika bilingual.

Instrumen yang digunakan untuk memperoleh data pengabdian ini yakni lembar observasi dan dokumentasi kegiatan. Lembar observasi digunakan pada saat monitoring penggunaan alat peraga fisika dan e-book panduan penggunaan bilingual di dalam pembelajaran fisika di kelas. Di akhir kegiatan, guru-guru yang menggunakan alat peraga diberikan angket respon pengguna untuk mengetahui penilai guru terhadap media pembelajaran tersebut. Kisi-kisi angket respon dapat dilihat pada tabel berikut.

Tabel 1. Indikator angket respon pengguna

\begin{tabular}{cl}
\hline No & Indikator \\
\hline 1 & Alat peraga mudah dipakai \\
2 & Alat peraga dapat digunakan untuk mencapai tujuan pembelajaran \\
3 & Alat peraga dapat digunakan untuk memperagakan suatu konsep fisika \\
4 & Konsep fisika pada alat peraga mudah diamati \\
5 & Alat peraga dapat menumbuhkan motivasi belajar siswa \\
6 & Panduan dapat dioperasikan di smartphone dengan lancar \\
7 & Struktur panduan penggunaan mudah dipahami \\
8 & Teks panduan mudah dibaca \\
9 & Bahasa inggris dalam panduan dapat dimengerti \\
10 & Panduan sesuai dengan alat peraga yang diberikan \\
\hline
\end{tabular}

Hasil angket respon kemudian dianalisis dan ditentukan kriterianya berdasarkan simpangan baku ideal. Interval yang digunakan untuk menentukan kriteria tiap pernyataan dapat dilihat pada Tabel 2 berikut.

Tabel 2. Kriteria penskoran

\begin{tabular}{cc}
\hline Interval Score & Kriteria \\
\hline $\mathrm{X}>4,2$ & Sangat baik \\
$3,4<\mathrm{X} \leq 4,2$ & Baik \\
$2,6<\mathrm{X} \leq 3,4$ & Cukup \\
$1,8<\mathrm{X} \leq 2,6$ & Buruk \\
$1,8>\mathrm{X}$ & Sangat buruk \\
\hline
\end{tabular}

\section{Hasil dan Diskusi}

Kegiatan pengabdian diawali dengan analisis kebutuhan sekolah mitra. Berdasarkan hasil wawancara dengan guruguru fisika di SMA YPK Merauke, diperoleh informasi bahwa alat peraga fisika disekolah tersebut masih sedikit. Padahal, alat peraga merupakan media belajar yang dapat dimanfaatkan untuk memvisualisasikan materi fisika yang 
cukup abstrak. Penggunaan alat peraga dalam pembelajaran berarti mengoptimalkan fungsi seluruh panca indra peserta didik. Melalui alat peraga peserta didik dapat meningkatkan efektivitas belajar dengan melihat, mendengar, meraba, serta menggunakan pikirannya secara logis dan realistis (Widiyatmoko \& Pamelasari, 2012). Penelitian yang dilaksanakan Wahyuningsih (2005) menunjukkan bahwa alat peraga dapat mengefektivkan kegiatan pembelajaran fisika. Selain itu, alat peraga dapat menumbuhkan motivasi belajar peserta didik sehingga proses pembelajaran (Dinata et al., 2017; Yunita \& Ilyas, 2019) tidak membosankan dan monoton. Dengan demikian, pada mata kuliah Fisika Eksperimen II yang dilaksanakan pada semester genap tahun ajaran 2019/2020, dikembangkan alat peraga fisika oleh mahasiswa pendidikan fisika universitas musamus dengan di bimbing oleh dosen pengampu Desy Kumala Sari, S.Pd., M.Pd.

\subsection{Pengadaan dan Pengenalan Alat Peraga Fisika Beserta E-Book Panduan Penggunaan Bilingual}

Alat peraga yang dikembangkan adalah alat peraga untuk praktikum Gerak Lurus Berubah Beraturan (GLBB), Hukum Hooke, dan Radiasi. Ketiga alat peraga tersebut dapat dilihat pada Fig. 1.Setelah alat peraga fisika dibuat, selanjutnya disusun panduan penggunaan alat peraga fisika dalam bahasa Indonesia maupun bahasa inggris. Selanjutnya panduan yang sudah ada di konversi kedalam bentuk e-book. Proses ini terjadi perubahan dari rencana awal, yakni mengkonversi menggunakan software sigil. Karena berbagai pertimbangan dari guru, panduan dikonversi dalam ekstensi .pdf agar mempermudah guru dan peserta didik dalam mengakses panduan yang dibuat. Tampilan panduan penggunaan alat peraga fisika bilingual disajikan pada Fig. 1. Panduan penggunaan juga dapat dilihat pada link https://drive.google.com/drive/u/0/my-drive

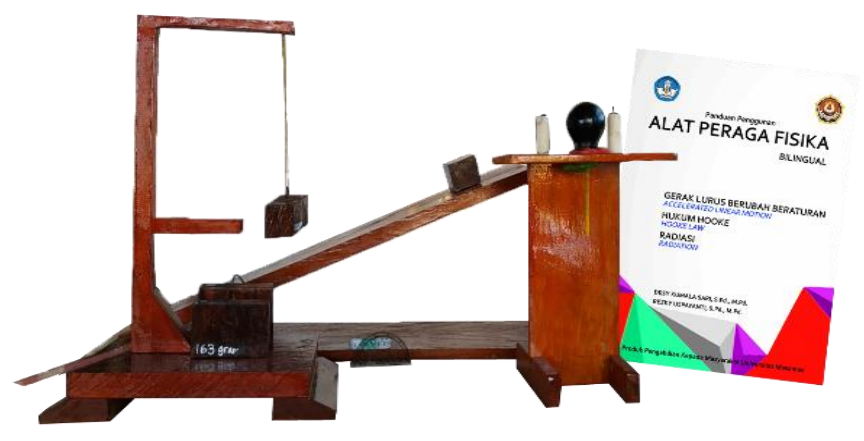

Fig. 1. Alat Peraga dan Panduan Penggunaan Alat Peraga Fisika Bilingual

Kegiatan selanjutnya yakni pengenalan dan penyerahan alat peraga fisika dan e-book panduan penggunaan alat peraga fisika bilingual yang dilaksanakan di SMA YPK Merauke. Kegiatan ini tadinya hanya direncanakan untuk kepala sekolah, wakasek, kepala laboratorim, serta guru-guru fisika, namun karena permintaan sekolah maka kegiatan ini kemudian dijadikan dalam bentuk pelatihan penggunaan alat peraga fisika dan e-book panduan penggunaan alat peraga fisika bilingual.

Kegiatan pengenalan dilaksanakan dengan memperkenalkan ketiga alat peraga yang dikembangkan kepada guru-guru yang hadir sebagai peserta. Peserta yang terlibat dalam kegiatan ini sebanyak 15 peserta yang berasal dari guru-guru di sekolah mitra. Selanjutnya kegiatan pengenalan ini dibawakan oleh tim PKM dengan dibantu oleh mahasiswa pendidikan fisika. Kegiatan ini mendapat perhatian yang sangat antusias dari para guru karena merupakan kegiatan yang pertama kali dilakukan disekolah yang berupa pengenalan alat peraga fisika.

Setelah alat peraga fisika diperkenalkan kepada guru-guru, selanjutnya dilaksanakan kegiatan penyerahan alat peraga di wakilkan oleh PLH SMA YPK Merauke dan Guru Fisika SMA YPK Merauke (Fig. 2). Pihak sekolah sangat mengapresi kegiatan ini karena sangat membantu ketersediaan media pembelajaran disekolah. Harapannya kedepan makin banyak penyediaan media pembelajaran bagi sekolah, selain itu merupakan motivasi bagi guru-guru untuk mengembangkan media pembelajaran sendiri. 


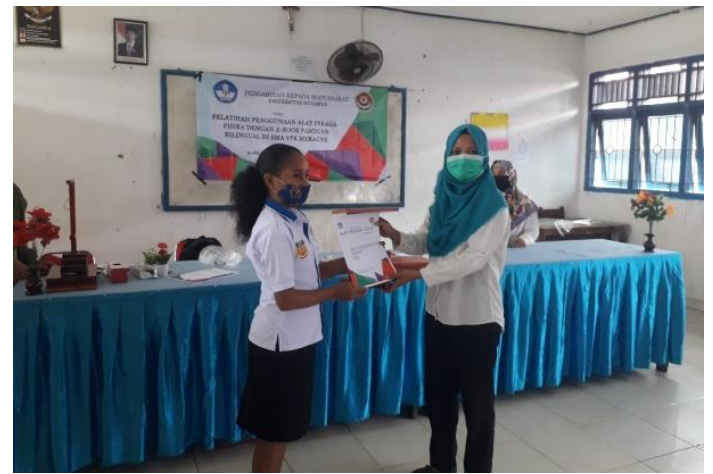

Fig. 2. Penyerahan alat peraga fisika dan (simbolis) e-book panduan penggunaan alat peraga fisika bilingual kepada pihak sekolah mitra

Pelaksanan kegiatan ini diterbitkan pada Arafura News tanggal 08 sampai dengan 09 Oktober 2020 dan juga terbit pada berita online pasificpos.com (https://www.pasificpos.com/tim-dosen-unmus-hibahkan-alat-peraga-fisika-karyamahasiswa/ ). Artikel tersebut memuat ungkapan dari pihak sekolah terkait kegiatan yang dilaksanakan tim PKM dari Universitas Merauke ini. Pihak sekolah menyatakan ungkapan terimakasih kepada tim PKM tas perhatiannya terhadap kelengkapan alat peraga fisika di sekolah mereka (Desy Kumala Sari et al., 2020). Selain itu, guru fisika juga sangat berterimakasih karena dengan adanya alat peraga yang dihibahkan dapat membantu guru dalam menjelaskan materi pembalajaran fisika yang abstrak.

\subsection{Pendampingan Penggunaan Alat Peraga}

Kegiatan ini dilaksanakan pada tanggal 09 November 2020. Pada kegiatan ini tim PKM mendampingi guru dalam mempersiapakan kegiatan pembelajaran menggunakan alat peraga fisika yang telah diserahkan. Pada pendampingan ini, guru fisika yang bersedia untuk didampingi atas nama Ibu Christin Susan Selvia Kailuhu, S.Pd. Beliau mengkonsultasikan penggunaan alat peraga hukum hooke untuk digunakan dalam pembelajaran fisika di dalam kelas (Fig. 3).

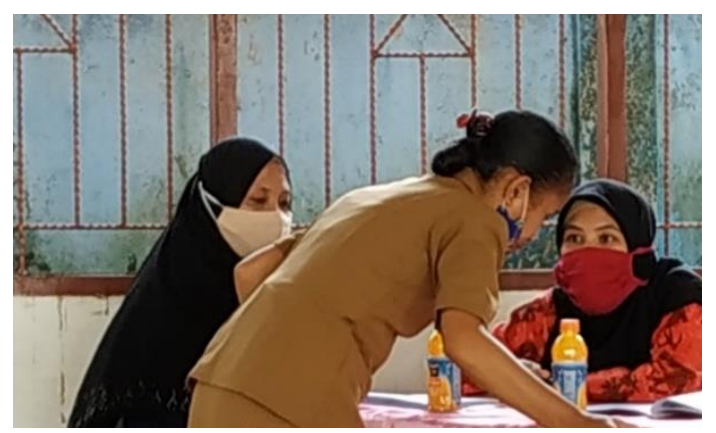

Fig. 3. Guru sedang mengkonsultasikan penggunaan alat peraga Hukum Hooke

Sebelum memulai pembelajaran, guru mempersiapkan sendiri alat peraga yang akan digunakan untuk menjelaskan konsep Hukum Hooke. Pada kegiatan ini guru tidak mengalami kesulitan sama sekali. Hal ini selain dikarenakan panduan penggunaan yang sudah disediakan, penggunaan alat peraga juga sudah di demonstrasikan pada kegiatan pengadaan alat peraga sebelumnya. Guru hanya diberikan arahan terkait konsep penggunaan alat peraga dalam pembelajaran. Pada akhirnya, konsep penggunaan alat peraga yang digunakan adalah berupa demonstrasi penggunaan alat dan praktikum skala kecil oleh beberapa peserta didik. 


\subsection{Monitoring}

Kegiatan monitoring ini dilaksakan ketika guru menerapkan pembelajaran fisika didalam kelas menggunakan alat perga, dalam pembelajaran ini menggunakan alat peraga hukum hooke. Pada pelaksanaan kegiatan ini tim PKM memperhatikan terkait kepraktisan alat peraga dalam pembelajaran dikelas. Tim PKM melakukan observasi selama pembelajaran dengan observer sebanyak 2 (dua) orang yang merupakan tim PKM sendiri. Kegiatan pembelajaran dilaksanakan sesuai dengan protokol kesehatan mengingat bahwa saat ini masih berada dalam masa pandemi COVID19. Peserta didik duduk dengan jarak \pm 1 meter.

Penggunaan alat peraga ini dimulai dengan penjelasan guru terkait penggunaan alat peraga kepada peserta didik. Kendala dalam kegiatan ini adalah tidak semua peserta didik memiliki smartphone sehingga arsip panduan penggunaan alat peraga fisika bilingual dalam bentuk hardcopy dijadikan media. Namun, guru menjelaskan bahwa sehari sebelum memulai kegiatan pembelajaran guru mengirimkan e-book panduan penggunaan alat peraga fisika bilingual kepada peserta didik yang memiliki smartphone. Setelah diberikan penjelasan, guru kemudian meminta tiga orang peserta didik untuk melakukan demonstrasi penggunaan alat peraga hingga mendapatkan hasil perhitungan dari data yang diperoleh (Fig. 4). Setelah kegiatan ini perhitungan dilakukan dengan peserta didik yang lainnya secara bersama-sama untuk memperoleh hasil. Guru membimbing kegiatan pembelajaran dengan baik. Selain itu, berdasarkan hasil observasi terlihat bahwa peserta didik sangat antusias dalam kegiatan pembelajaran menggunakan alat peraga hukum hooke.

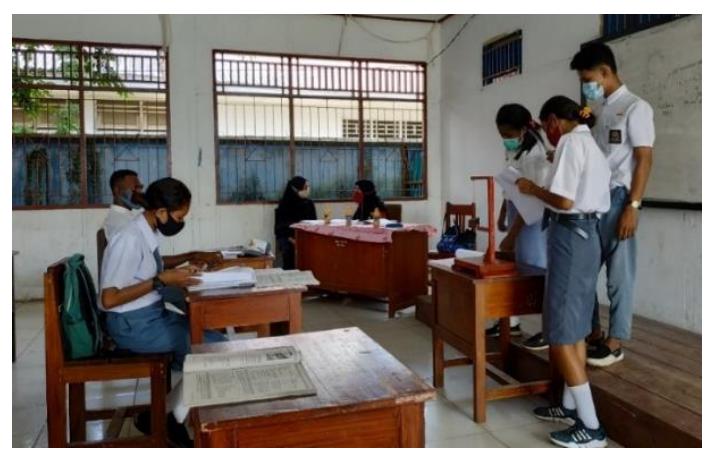

Fig. 4. Peserta didik melaksanakan kegiatan praktikum hukum hooke

Kegiatan monitoring ini berjalan dengan lancar sesuai dengan rencana, namun belum memanfaatkan e-book panduan penggunaan alat peraga fisika bilingual secara maksimal. Hal ini dikarenakan tidak semua peserta didik memiliki smarphone ataupun PC.

\subsection{Respon Pengguna terhadap Alat Peraga}

Hasil angket respon guru-guru dapat dilihat pada Fig. 5. Secara keseluruhan, indicator respon alat peraga berada dalam kategori baik dan sangat baik. Menurut guru, alat peraga dapat digunakan untuk mendukung proses pembelajaran fisika. Konsep fisikanya dapat diamati dan peserta didik pun termotivasi menggunakannya. Kendala utama yang dimiliki guru berkaitan dengan e-book panduan penggunaannya karena tidak semua peserta didik memiliki smartphone. 


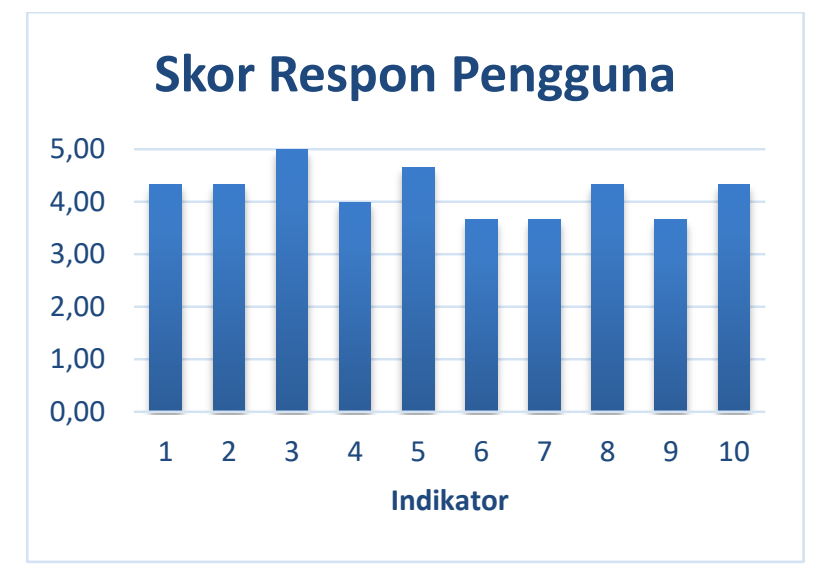

Fig. 5. Respon guru terhadap alat peraga fisika dan e-book panduan penggunaan

\section{Kesimpulan}

Berdasarkan kegiatan pengadaan alat peraga beserta e-book panduan bilingual yang telah dilaksanakan pada SMA YPK Merauke, disimpulkan bahwa kegiatan ini telah memberikan respon terhadap permasalahan mitra, permasalahan mitra berupa alat peraga yang masih belum lengkap, dengan adanya kegiatan ini sekolah mitra mendapatkan tambahan alat peraga fisika yang dapat digunakan dalam pembelajaran; Permasalahan mitra berupa belum tersedianya panduan penggunggunaan alat peraga fisika yang ada, melalui kegiatan ini disediakan alat peraga fisika beserta buku panduannya; Permasalahan mitra berupa panduan penggunaan yang sering hilang dalam bentuk cetakan, melalui kegiatan ini disediakan panduan penggunaan dalam bentuk e-book dan juga cetakan sebagai arsip; Permasalahan mitra berupa kemampuan bahasa inggris peserta didik yang masih rendah, dengan adanya kegiatan ini paduan disediakan dalam 2 (dua) bahasa yakni bahasa Indonesia dan bahasa inggris sehingga paling tidak membiasakan peserta didik dalam mengenal kosakata bahasa inggris dalam ilmu fisika.

Saran dalam kegiatan ini adalah, perlu kerjasama antara guru dan tim PKM dalam pembuatan alat peraga agar alat yang dikembangkan sesuai dengan kebutuhan guru dalam melaksanakan pembelajaran di dalam kelas maupun diluar kelas. Selain itu, alat peraga yang sudah diserahkan kepada pihak sekolah perlu dilakukan kegiatan lanjutan berupa pembuatan video pembelajaran untuk menjawab tantangan pembelajaran jarak jauh di masa pandemi COVID-19 ini.

\section{Acknowledgements}

Terimakasih kepada Rektor Universitas Musamus dan LP2M Universitas Musamus untuk bantuan dana penelitian pada skim Pengabdian Kepada Masyarakat. Kegiatan pengabdian ini didasarkan pada kontran Pengabdian Kepada Masyarakat Tahun Anggaran 2020 Nomor: 181.3/UN52.8/PM/2020.

\section{References}

Cahya Dinata, P. A., Rahzianta, R., \& Suparwoto, S. (2018). The Students' Mental Model about Newton's Third Law In Indonesia. Unnes Science Education Journal, 7(2). https://doi.org/10.15294/usej.v7i2.23366

Dinata, P. A.C., \& Suparwoto. (2018). Problem-based learning with jukung and balogo to improve students' mental model in south borneo. Journal of Physics: Conference Series, 1097(1). https://doi.org/10.1088/1742-6596/1097/1/012026

Dinata, Pri Ariadi Cahya, Sari, D. K., \& Suparwoto, S. (2020). Problem-Based Online Learning Assissted by Whatsapp to Facilitate The Scientific Learning of 2013 Curriculum. Berkala Ilmiah Pendidikan Fisika, 8(1), 1-11. 
https://doi.org/10.20527/bipf.v8i1.7647

Dinata, Pri Ariadi Cahya, Sastradika, D., \& Safitri, A. D. (2017). Implementation of Gasing Learning in ARCS Learning Strategy to Enhance Students' Motivation in 9th Grade of Indonesian Junior High-School. IJPTE: International Journal of Pedagogy and Teacher Education, 1(2), 80-92. https://doi.org/10.20961/ijpte.v1i2.15286

Fitriani, N. (2013). Pengembangan Apat PEraga Sains Fisika dengan Memanfaatkan Sampah Anorganik Materi Kelistriken dan Kemagnetan Pada Siswa SMP/MTS. Universitas Islam Negeri Sunan Kalijaga.

Kause, M. C. (2019). Rancang Bangun Alat Peraga Fisika Berbasis Arduino (Studi Kasus Gerak Jatuh Bebas). Cyclotron, 2(1). https://doi.org/10.30651/cl.v2i1.2511

Octaviana, K., \& Supriyono. (2017). Pengembangan alat peraga hukum kepler sebagai media pembelajaran fisika pada amateri hukum kepler. Jurnal Inovasi Pendidikan Fisika, 06(02), 5-9.

Preliana, E. (2015). Pengembangan Alat Peraga Sains Fisika Berbasis Lingkungan untuk MAteri Listrik Statis pada Siswa KElas IX SMP Negeri 3 Pleret. JRKPF UAD, 2(1), 6-11.

Pujani, N. M. (2015). Pengembangan Perangkat Praktikum Ilmu Pengetahuan Bumi dan Antariksa Berbasis Kemampuan Generik Sains untuk Meningkatkan Keterampilan Laboratorium Calon Guru Fisika. JPI (Jurnal Pendidikan Indonesia), 3(2), 471-484. https://doi.org/10.23887/jpi-undiksha.v3i2.4463

Sari, D. K., Supahar, \& Ralmugiz, U. (2018). The influence of android-based isomorphic physics (Forfis) application on analogical transfer and self-diagnosis skill of students at SMA Negeri 3 Kupang. Jurnal Pendidikan IPA Indonesia, 7(2), 154-161. https://doi.org/10.15294/jpii.v7i2.14268

Sari, D., Simbolon, M., \& Reski, A. (2019). Utilization Isomorphic Physics (FORFIS) Application to Improve Physics Analogical Transfer Skill of Senior High School Students. 2nd International Conference on Social Science (ICSS 2019), 383, 109-112. https://doi.org/10.2991/icss-19.2019.206

Sari, Desy Kumala, Uspayanti, R., \& Dinata, P. A. C. (2020). Tim Dosen Unmus Hibahkan Alat Peraga Fisika Karya Mahasiswa.

Wahyuningsih, S. (2005). Efektivitas Penggunaan Alat Peraga IPA (Fisika) Kelas I SLTPN Yogyakarta. Jurnal Penelitian Dan Evaluasi Pendidikan, 7(2), 196-208. https://doi.org/10.21831/pep.v7i2.2020

Widiyatmoko, A., \& Pamelasari, S. D. (2012). Pembelajaran berbasis proyek untuk mengembangkan ALAT peraga IPA dengan memanfaatkan bahan bekas pakai. Jurnal Pendidikan IPA Indonesia, 1(1), 51-56. https://doi.org/10.15294/.v1i1.2013

Yunita, I., \& Ilyas, A. (2019). Efektivitas alat peraga induksi elektromagentik terhadap kemampuan berpikir kritis peserta didik. Indonesian Journal of Science and Mathematics Education, 02(2), 245-253. 